\title{
Hyperkyphosis
}

\section{Tal Grenader}

Received: 8 June 2011/ Accepted: 30 June 2011/Published online: 16 July 2011 (C) SIMI 2011

An 83-year-old woman with Alzheimer disease underwent computed tomography of chest, abdomen and pelvis as part of an evaluation of locally recurrent estrogen positive breast cancer. Although no metastatic disease was present, severe osteoporosis and multiple vertebrae fractures were noted.
Osteoporotic anterior compression fractures of adjacent vertebral bodies of D7-D8 with loss of height of more than $50 \%$ (arrows, Fig. 1a) as a result of which the spine itself has undergone spatial transformation with change of kyphotic angle to $84^{\circ}$ (normal range $20-30^{\circ}$ ) (Fig. 1b).
Fig. 1 Sagital view of CT scan showed osteoporotic anterior compression fractures of adjacent vertebral bodies transformation with change of kyphotic angle to $84^{\circ}$
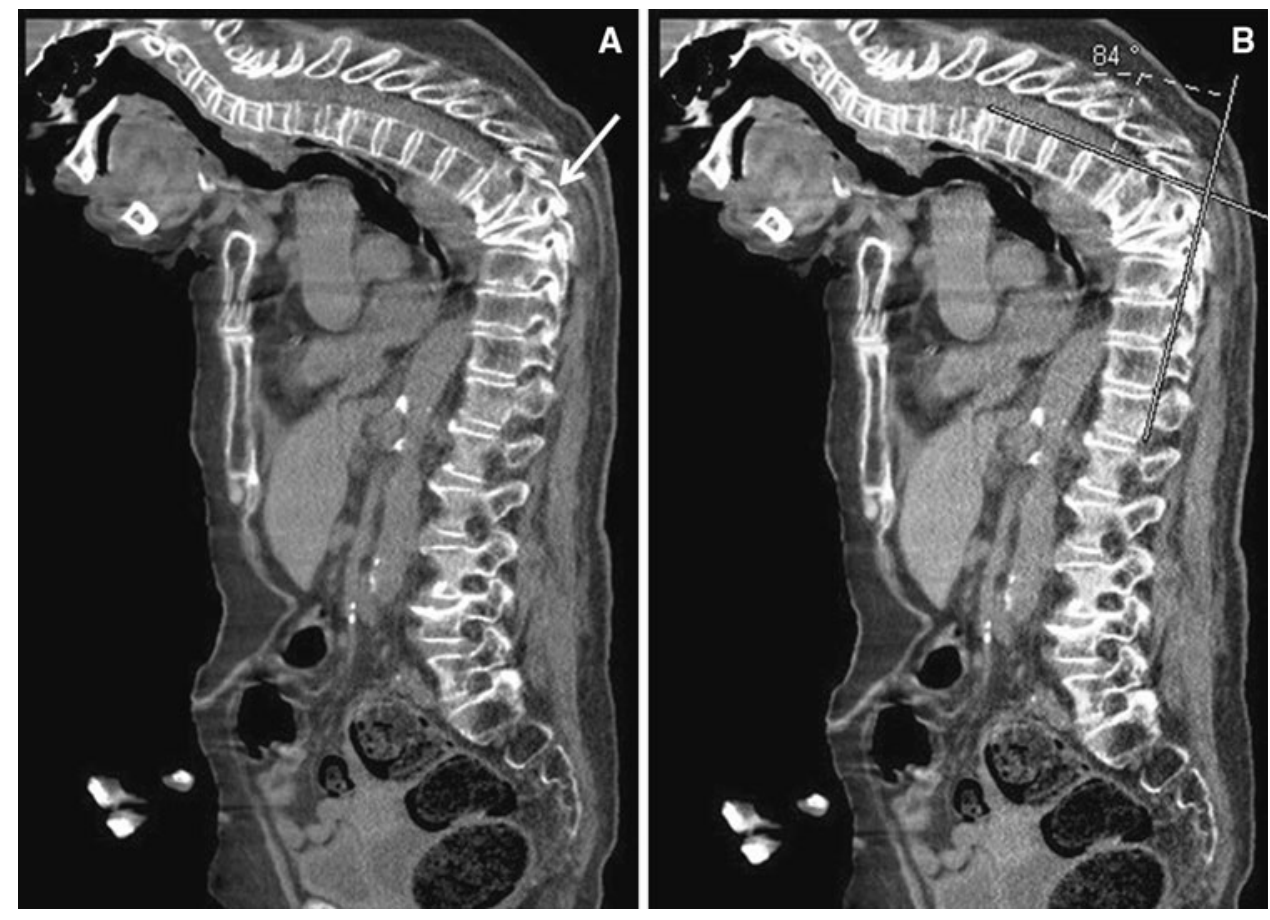

T. Grenader ( $\square)$

Department of Oncology, Sha' are Zedek Medical Center,

P.O. Box 3235, 91031 Jerusalem, Israel

e-mail: talgrenader65@hotmail.com 
Geometrically, instead of its normal (straight line vertically oriented) form, the spine has become almost a rightangle like curvature, such that two adjacent rectangles have become acute-angled scalene triangles.

Between 20 and $40 \%$ of the elderly may develop an excessive degree of kyphosis, called hyperkyphosis. Vertebral fractures are present in $\sim$ one-third of the severe kyphosis cases in elderly people. This condition may be associated with severe adverse health outcomes, such as poor pulmonary and heart function, and physical condition [1].

Conflict of interest None.

\section{Reference}

1. Kado DM, Prenovost K, Crandall C (2007) Narrative review: hyperkyphosis in older persons. Ann Intern Med 147:330-338 